\title{
Article
}

\section{Occupational airborne exposure in relation to Chronic Obstructive Pulmonary Disease (COPD) and lung function in individuals without childhood wheezing illness: A 50-year cohort study}

Tagiyeva, Nara, Sadhra, Steven, Mohammed, Nuredin, Fielding, Shona, Devereaux, Graham, Teo, Ed, Ayres, Jon and Douglas, Graham

Available at http://clok.uclan.ac.uk/16612/

Tagiyeva, Nara ORCID: 0000-0002-6398-572X, Sadhra, Steven, Mohammed, Nuredin, Fielding, Shona, Devereaux, Graham, Teo, Ed, Ayres, Jon and Douglas, Graham (2017) Occupational airborne exposure in relation to Chronic Obstructive Pulmonary Disease (COPD) and lung function in individuals without childhood wheezing illness: A 50-year cohort study. Environmental Research, 153 . pp. 126-134. ISSN 0013-9351

It is advisable to refer to the publisher's version if you intend to cite from the work. http://dx.doi.org/10.1016/j.envres.2016.11.018

For more information about UCLan's research in this area go to http://www.uclan.ac.uk/researchgroups/ and search for <name of research Group>.

For information about Research generally at UCLan please go to http://www.uclan.ac.uk/research/

All outputs in CLoK are protected by Intellectual Property Rights law, including Copyright law. Copyright, IPR and Moral Rights for the works on this site are retained by the individual authors and/or other copyright owners. Terms and conditions for use of this material are defined in the policies page. 


\section{Occupational airborne exposure in relation to Chronic Obstructive Pulmonary Disease (COPD) and lung function in individuals without childhood wheezing illness: a 50-year cohort study}

Nara Tagiyeva ${ }^{1}, \mathrm{PhD}$, Steven Sadhra ${ }^{2}$, Nuredin Mohammed $^{3}, \mathrm{PhD}$, Shona Fielding ${ }^{4}, \mathrm{PhD}$, Graham Devereux ${ }^{4}, \mathrm{PhD}, \mathrm{Ed} \mathrm{Teo}^{5}$, Jon Ayres ${ }^{3}$, J Graham Douglas ${ }^{4}$

${ }^{1}$ School of Dentistry, University of Central Lancashire, Preston, PR1 2EH, UK

${ }^{2}$ Occupational and Environmental Medicine, Institute of Clinical Sciences, College of Medical and Dental Sciences, University of Birmingham, Edgbaston, Birmingham, B15 2TT, UK

${ }^{3}$ Institute of Applied Health Research, College of Medical and Dental Sciences, University of Birmingham, Edgbaston, Birmingham, B15 2TT, UK

${ }^{4}$ Institute of Applied Health Sciences, University of Aberdeen, Aberdeen, AB25 2ZG, UK

${ }^{5}$ Academic Clinical Programme for Medicine, Singapore General Hospital, Outram Road, Singapore 169608

Corresponding author: Nara Tagiyeva, Room HA132, Harrington Building, University of Central Lancashire, tagiyeva@ hotmail.com, +44 1772896317 


\begin{abstract}
Background: Evidence from longitudinal population-based studies relating occupational exposure to the full range of different forms of airborne pollutants and lung function and airway obstruction is limited.
\end{abstract}

Objective: To relate self-reported COPD and lung function impairment to occupational exposure to different forms of airborne chemical pollutants in individuals who did not have childhood wheeze.

Methods: A prospective cohort study was randomly selected in 1964 at age 10-15 years and followed up in 1989, 1995, 2001 and 2014 (aged 58-64) by spirometry and respiratory questionnaire. Occupational histories were recorded in 2014 and occupational exposures assigned using an airborne chemical job exposure matrix. The risk of COPD and lung function impairment was analyzed in subjects, who did not have childhood wheeze, using logistic and linear regression and linear mixed effects models.

Results: 237 subjects without childhood wheeze (mean age 60.6 years, $47 \%$ male) were analyzed. There was no association between any respiratory outcomes and exposure to gases, fibers, mists or mineral dusts and no consistent associations with exposure to fumes. Reduced $\mathrm{FEV}_{1}$ was associated with longer duration (years) of exposure to any of the six main pollutant forms - vapors, gases, dusts, fumes, fibers and mists (VGDFFiM) with evidence of a dose-response relationship (p-trend=0.004). Exposure to biological dusts was associated with self-reported COPD and $\mathrm{FEV}_{1}<$ Lower Limit of Normal (LLN) (adjusted odds ratio [95\%CI] 4.59 [1.15, 18.32] and 3.54 $[1.21,10.35]$ respectively), and reduced $\mathrm{FEF}_{25-75 \%}$ (adjusted regression coefficients [95\% CIs] $9.11[-17.38,-0.84]$ respectively). Exposure to vapors was associated with self-reported COPD and $\mathrm{FEV}_{1}<\mathrm{LLN}$ (adjOR $6.46[1.18,35.37]$ and 4.82 [1.32, 17.63]). Longitudinal analysis demonstrated reduced $\mathrm{FEV}_{1}$ and $\mathrm{FEF}_{25-75 \%}$ associated with exposure to biological dusts or vapors. 
Conclusions: People with no history of childhood wheezing who have been occupationally exposed to biological dusts or vapors or had longer duration of lifetime exposure to any VGDFFiM are at a higher risk of reduced lung function at age 58-64 years. Occupational exposure to biological dusts or vapors also increased the risk of self-reported COPD.

Keywords: COPD, lung function, occupational exposure, airborne pollutants, job exposure matrix 
Funding source: Chest, Heart and Stroke Scotland, grant ref R13/A148.

The funder had no role in study design, data collection, analysis and interpretation, writing of the manuscript, and in the decision to submit the manuscript for publication. All authors had full access to all the data in the study. The corresponding author had final responsibility for the decision to submit for publication.

Review and approval: National Research Ethics Service Committee - North of Scotland, ref 13/NS/0038

${ }^{2}$ Institute of Applied Health Sciences, University of Aberdeen, Aberdeen, AB25 2ZG, UK 


\section{Introduction}

Occupational factors play an important role in adult-onset asthma (population-attributable risk (PAR) 17\%) and chronic obstructive pulmonary disease (COPD) (PAR 15-20\%) [1]. Occupational exposure to the main airborne pollutant forms, i.e. vapors, gases, dusts or fumes (VGDF) has been linked to higher prevalence, incidence and severity of COPD [2], even after adjustment for smoking, in both occupational and population-based studies, the majority of which were cross-sectional [3]. Evidence from longitudinal population-based studies is, however, scarce and less consistent [4-7]. Most longitudinal studies have relatively short follow-up periods with only one study reporting changes in lung function in relation to occupational exposure to VGDF over 25 years [8].

Long-term prospective studies are needed to explore the relationship between occupational exposure and adult onset of obstructive respiratory disorders which have not been influenced by preceding respiratory symptoms and/or healthy worker effect [9]. The Aberdeen-based WHEASE (What Happens Eventually to Asthmatic children: Sociologically and Epidemiologically) cohort 1964-2014 is one of the longest follow-up studies of children in the world with a focus on airways disease. Moreover, clinical assessment of this cohort provides an opportunity to link occupational exposures to respiratory outcomes in adult life in subjects without childhood wheezing illness.

This study investigates whether lifetime occupational exposure to different airborne pollutant forms increases the likelihood of self-reported COPD, spirometry-defined airflow obstruction, and lung function impairment at age 58-64 years among individuals with no history of childhood wheezing illness. This study also investigates the longitudinal impact of occupational exposures on lung function over 25 years of follow-up. 


\section{Materials and Methods}

\subsection{Subjects}

The WHEASE cohort has been described in detail elsewhere [10]. Briefly, in 1964 a random sample of 2511 (20\% of all Aberdeen schoolchildren aged 10-15 years), was selected [11] and administered the parent-completed Medical Research Council (MRC) questionnaire [12]. Those with parentally reported history of ever wheeze were clinically assessed by a pediatrician and categorized into having childhood asthma or childhood wheezy bronchitis - now commonly known as virusassociated wheeze. Children without parent-reported history of ever wheezing were categorized as childhood "non-wheezers". The cohort was invited for the follow up in 1989 (aged 35-40), 1995 (aged 41-46), 2001 (aged 47-52), and 2014 (aged 58-64) [10;13-15] (Table 1). 
Table 1. The WHEASE cohort recruitment and follow up

\section{Original cohort}

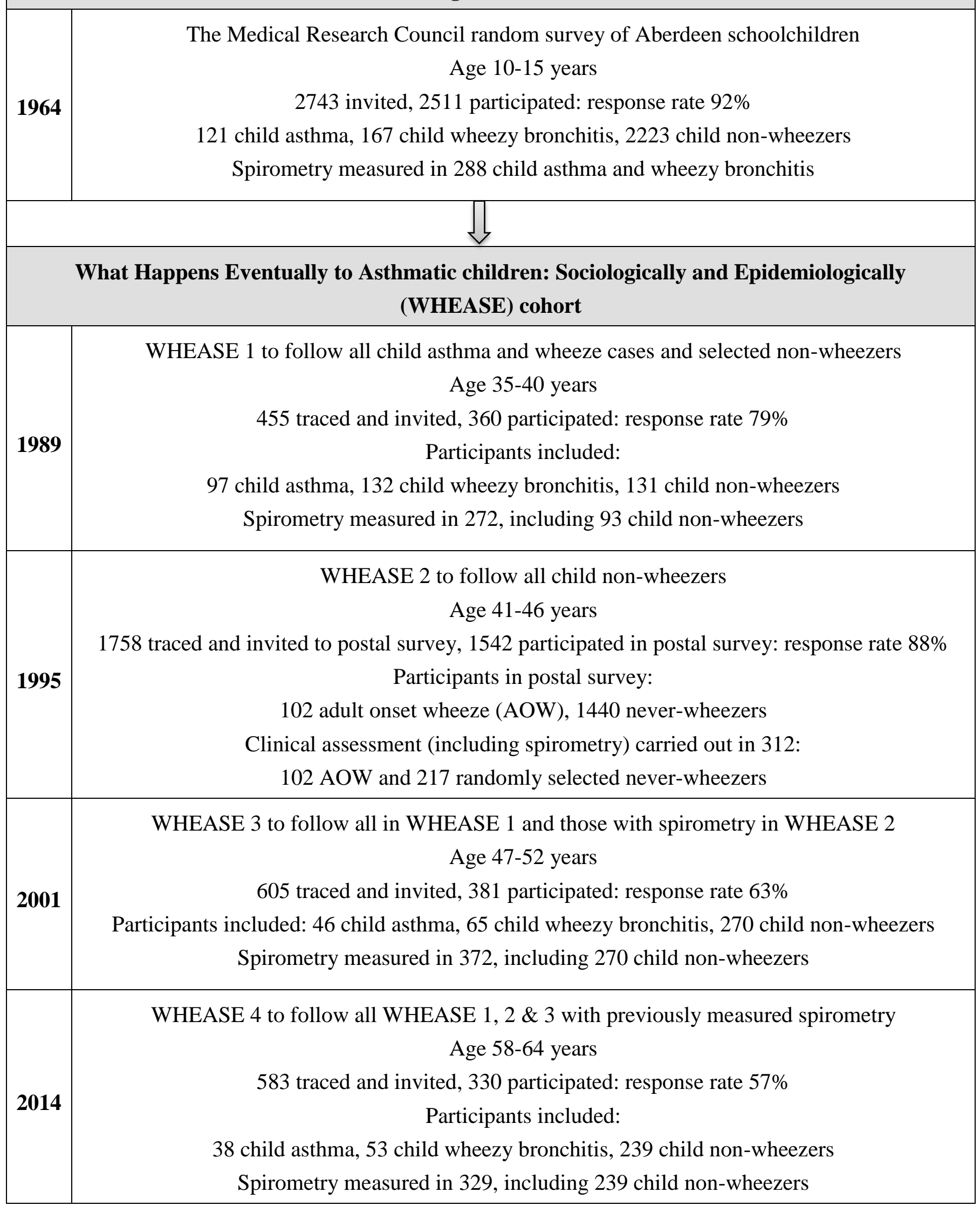


In 2014 all individuals with spirometry who took part in at least one previous follow up were traced and invited to take part. Only childhood "non-wheezers" were included in the current study of occupational exposure and adult airway disease, i.e. those whose parents in 1964 reported that their child had no history of ever wheezing. Subjects who in 1964 were categorized as having childhood asthma or childhood wheezy bronchitis/virus-associated wheeze were excluded from the current study.

\subsection{Health assessments and outcomes}

Each follow up between 1989 and 2014 included the updated version of the MRC respiratory questionnaire [16] administered during in-person interview and spirometry with recorded forced expiratory volume in one second $\left(\mathrm{FEV}_{1}\right)$ and forced vital capacity (FVC). Spirometry was performed according to internationally accepted guidelines. The 2014 spirometry followed ATS/ERS guidelines [17] with pre- and post- administration of $400 \mu \mathrm{g}$ salbutamol using a Vitalograph Compact II spirometer (Vitalograph, Buckingham, UK). Measurement of forced expiratory flow over the middle half of $\mathrm{FVC}\left(\mathrm{FEF}_{25-75}\right)$, which reflects small airway function, was also recorded in 2014.

Socio-demographic characteristics related to health status, i.e. cigarette smoking and deprivation were ascertained at each follow up. A history of cigarette smoking was assessed by pack year smoking histories, with a pack year defined as twenty cigarettes smoked every day for one year. The highest educational qualification was used as an indicator of childhood and adulthood socioeconomic status (SES). 


\subsection{Occupational exposure}

The 2014 follow up assessment also included a record of lifetime occupational history, including job titles, main job tasks, industry type, year when jobs started and stopped, and type of employment for each job (full- or part-time), obtained during the interview. Occupational histories were obtained for all jobs held for at least 12 months.

Free-text descriptions of occupations and industries for all lifetime jobs were coded into four-digit Standard Occupational Classification (SOC2000) codes developed by the UK Office for National Statistics [18] using the Computer Assisted Structured Coding Tool (CASCOT) [19]. This generates certainty scores (1-100\%), indicators of the degree of certainty, that the given code is correct. The chosen coding strategy was to accept CASCOT derived codes scored $>50 \%$ in a fully automatic mode and to code manually those scored $\leq 50 \%$. In the automatic mode, the code with the highest score was automatically accepted. This coding strategy has been shown to have $91 \%$ agreement with manually coded occupations [20].

Occupational exposure to the complete range of airborne pollutant forms was assigned to each SOC code for each job held using the airborne chemical exposure job exposure matrix (ACEJEM). The ACEJEM [21] assigns exposure to the broad pollutants forms: vapors, gases, dusts, fumes, fibers and mists (VGDFFiM) as well as their sub-fractions including mineral dusts, biological dusts and diesel fumes to each of the 353 SOC2000 codes. Exposures are assigned based on a set of a priori defined job descriptors: definitions of pollutant types and guidelines for assigning average exposures (by consideration of exposure determinants), and are independent of any respiratory outcomes. The ACEJEM enables occupational exposure to be evaluated as a binary exposure (exposed and non-exposed) and by the level of exposure (low, medium and high). The ACEJEM is 
based on workplace exposure conditions between 2000 and 2013 and does not take account of any respiratory protective equipment (RPE) that may have been used by individuals in their job roles.

\subsection{Statistical Analysis}

The primary outcomes were self-reported COPD, defined by an affirmative response to the question "Have you ever had or been told that you have COPD", lung function and airflow obstruction at age 58-64 years and overall difference in lung function data collected during the 25-year follow-up period between the exposed and not exposed.

Spirometric indices were expressed as \% predicted as defined by the ERS Global Lung Initiative, 2012 [22]. Reduced $\mathrm{FEV}_{1}$ was defined as a post-bronchodilator $\mathrm{FEV}_{1}$ less than lower 95\% confidence limit of the internationally agreed predictive equations for normality (LLN). Airflow obstruction was defined as a post-bronchodilator $\mathrm{FEV}_{1} / \mathrm{FVC}<\mathrm{LLN}$ [17;22].

Occupational exposures to six main pollutant forms, vapors, gases, dusts, fumes, fibers and mists (VGDFFiM), in any jobs held and their sub-fractions, biological dusts, minerals and diesel fumes, were categorized as ever exposed versus never exposed. Secondly categories of cumulative exposure duration (short, medium and long) were generated using tertiles of cumulative lifetime duration of exposure in years to any and each of the VGDFFiM as well as the three pollutant subcategories. Exposures in the longest and current/last held jobs were examined in separate models. The reference categories in each analysis were those without the specific exposure of interest. 
Demographic characteristics were described using number and percentage if categorical variables or mean and standard deviation if continuous (as normally distributed). Normality was assessed by skewness and kurtosis tests and histograms. Logistic and linear regression analyses were implemented for binary and continuous outcomes respectively with adjustment for confounders (sex, pack years of smoking, highest education qualification). Different models were fitted: model A looked at the binary variable of 'any airborne pollutant', while separate models B looked at exposure to each of the six main pollutant forms, and also separate models $\mathrm{C}$ looked at exposure to each sub-group of pollutant on its own. Associations were further explored by categorizing the exposure duration into none, short, medium and long exposure as described above. The effects of an exposure on the outcome were presented as odds ratios (OR) for binary outcomes and regression coefficients for continuous outcomes with an appropriate $95 \%$ confidence interval (CI) for each.

Linear mixed effect models with unstructured covariance were used to analyze the overall difference in all $\mathrm{FEV}_{1}, \mathrm{FVC}$ and $\mathrm{FEF}_{25-75 \%}$ data collected between 1989 and 2014 between the exposed and non-exposed. Random effects were participant and participant*time with fixed effects of time and the confounding variables. Time was entered as a continuous variable taking the values $0,6,12$ and 25 years to represent the four assessments beginning in 1989. Inclusion of an interaction term for time and exposure to individual substances allowed the production of estimates of change in outcome between exposed and non-exposed. Models were adjusted for sex, pack years of smoking, highest education qualification and age in 1989.

Participants who did not provide an occupational history were excluded from the analysis. Jobs with less than one year duration were excluded from the estimation of exposure. Analyses were performed using IBM SPSS v22.0 (Armonk, NY, USA) and SAS v9.3 (SAS Institute Inc., Cary, USA). 


\section{Results}

Out of 239 WHEASE subjects in 2014 who did not have childhood wheezing illness, 237 provided occupational histories and formed the current study cohort. The mean (SD) age of the cohort was $60.6(1.5)$ years and $47 \%$ were male. Approximately $15 \%(n=34)$ of the cohort reported a diagnosis of asthma, 6\% $(\mathrm{n}=15)$ a diagnosis of COPD, 8\% (n=20) had $\mathrm{FEV}_{1}<\mathrm{LLN}$ and 27\% (n=63) had spirometry-defined airflow obstruction $\left(\mathrm{FEV}_{1} / \mathrm{FVC}<\mathrm{LLN}\right)$. Characteristics of the study participants are detailed in Table 2. 
Table 2 Main demographic and health indicators of the WHEASE study participants with available occupational history in 2014 who had had no childhood wheeze, $\mathrm{n}$ analyzed=237

\begin{tabular}{|c|c|}
\hline \multicolumn{2}{|c|}{ Socio-demographic characteristics } \\
\hline Male sex, n (\%) & $111(46.8)$ \\
\hline Age, years, mean (SD) & $60.6(1.5)$ \\
\hline BMI, $\mathrm{kg} / \mathrm{m}^{2}$, mean $(\mathrm{SD})$ & $28.4(5.5)$ \\
\hline Smoking ever, n (\%) & $124(52.3)$ \\
\hline Smoking currently, n (\%) & $41(17.3)$ \\
\hline Current exposure to $\mathrm{ETS}^{\dagger}, \mathrm{n}(\%)$ & $42(17.7)$ \\
\hline University degree and higher, $\mathrm{n}(\%)$ & $42(17.7)$ \\
\hline Current work status, n (\%) & \\
\hline Full-time & $110(46.4)$ \\
\hline Part-time & $57(24.1)$ \\
\hline Unemployed & $6(2.5)$ \\
\hline Retired & $44(18.6)$ \\
\hline Not working due to ill health & $20(8.4)$ \\
\hline Clinical, questionnaire-based, $n(\%)$ & \\
\hline Self-reported asthma & $34(14.7)$ \\
\hline Self-reported COPD & $15(6.3)$ \\
\hline Spirometry post bronchodilator & \\
\hline $\mathrm{FEV}_{1}, \%$ predicted, mean (SD) & $97.2(16.3)$ \\
\hline FVC, $\%$ predicted, mean (SD) & $108.6(15.5)$ \\
\hline $\mathrm{FEF}_{25-75 \%}, \%$ predicted, mean $(\mathrm{SD})$ & $77.8(33.6)$ \\
\hline $\mathrm{FEV}_{1}<\mathrm{LLN}, \mathrm{n}(\%)$ & $20(8.4)$ \\
\hline $\mathrm{FEV}_{1} / \mathrm{FVC}<\mathrm{LLN}, \mathrm{n}(\%)$ & $63(26.6)$ \\
\hline
\end{tabular}

${ }^{\dagger}$ Environmental tobacco smoke 


\subsection{Occupational exposure to airborne chemical pollutants}

Study participants had between one and six different jobs in their lifetime (median 2, IQR 2-3). Based on the whole occupational history, the most commonly reported occupations were elementary storage occupations (e.g. warehouse assemblers, foremen, loaders) and telecommunications engineers among men and cleaning, administrative occupations and sales assistants among women. Administrative and corporate managerial occupations were reported as most common among the longest jobs held.

Lifetime occupational exposure to the different airborne pollutant forms is presented in Table 3. More than two thirds of the participants had occupational exposure to at least one airborne pollutant at some point in their life with dusts being the most common pollutants (66\% exposed), followed by vapors $(53 \%)$ and fumes $(38 \%)$. Most common exposures to airborne pollutants by occupation in the WHEASE cohort are shown in Table E1, Online supplement.

Men were more commonly exposed to any airborne pollutants compared to women (VGDFFiM, $88 \%$ vs $60 \%, \mathrm{p}<0.001$ ), and also to all dusts and mineral dusts, all fumes and diesel fumes, gases, and fibers (all $\mathrm{p}<0.001)$. There was no gender difference in the prevalence of occupational exposure to vapors, mists, and biological dusts (data not shown). 
Table 3 Lifetime occupational exposures to airborne pollutants and duration of exposure calculated within those exposed among the WHEASE study participants, who had had no childhood wheeze, $\mathrm{n}$ analyzed $=237$

\begin{tabular}{|c|c|c|}
\hline Occupational exposures to & $\begin{array}{l}\text { Exposed ever, } \\
\text { n }(\%)\end{array}$ & $\begin{array}{l}\text { Duration of exposure, } \\
\text { years, median (IQR) }\end{array}$ \\
\hline $\begin{array}{l}\text { Any airborne pollutants } \\
\text { (VGDFFiM) }\end{array}$ & $173(73.0)$ & $31.0(18.0-42.0)$ \\
\hline \multicolumn{3}{|l|}{ Individual pollutant forms } \\
\hline Vapors & $125(52.7)$ & $21.5(10.0-31.75)$ \\
\hline Gases & $86(36.3)$ & $19.0(7.0-33.0)$ \\
\hline Dusts $^{\mathrm{a}}$ & $156(65.8)$ & $26.5(14.0-40.0)$ \\
\hline Fumes & $89(37.6)$ & $23.0(8.5-35.0)$ \\
\hline Fibers & $66(27.8)$ & $17.5(6.25-34.0)$ \\
\hline Mists & $82(34.6)$ & $19.5(7.75-32.25)$ \\
\hline \multicolumn{3}{|l|}{ Sub-categories of pollutants } \\
\hline Biological dusts $^{\mathrm{a}}$ & $100(42.2)$ & $18.0(7.0-31.75)$ \\
\hline Mineral dusts $^{\mathrm{a}}$ & $116(48.9)$ & $22.5(7.0-38.25)$ \\
\hline Diesel fumes & $55(23.2)$ & $20.0(7.0-30.0)$ \\
\hline
\end{tabular}

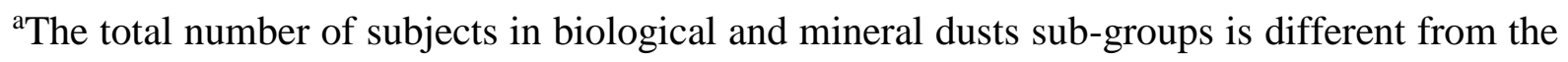
number of subjects in all dusts category, as some of the subjects had been assigned as exposed to both types of dusts. 


\subsection{Cross-sectional analysis of lung function outcomes in relation to occupational exposure to}

airborne chemical pollutants

Tables 4 and 5 present the results of unadjusted and adjusted logistic and linear regression analyses of the relationship between the outcomes in 2014 and exposure to airborne pollutants. As individuals were likely to be exposed to more than one pollutant, individuals' exposure assignment to one pollutant did not necessarily exclude exposure assignments to other pollutants, e.g. the total number of subjects in biological and mineral dusts sub-groups was different from the number of subjects in all dusts category, as some of the subjects had been assigned as exposed to both types of dusts. The significant associations observed in the unadjusted models between exposure to biological, but not mineral dusts, and self-reported COPD, $\mathrm{FEV}_{1}<\mathrm{LLN}$, and reduced $\mathrm{FEF}_{25-75 \%}$ predicted were confirmed in the adjusted models (Tables 4 and 5). In addition, exposure to vapors was associated with a 6-fold increase in COPD and 5-fold increase in the likelihood of having $\mathrm{FEV}_{1}<\mathrm{LLN}$. Self-reported COPD was also associated with exposure to gases, any fumes, diesel fumes and mineral dusts in the unadjusted models. However, the associations became nonsignificant in the adjusted models. No association was found between any exposure and $\mathrm{FEV}_{1} / \mathrm{FVC}<\mathrm{LLN}$ or between exposure to VGDFFiM and any outcome in the adjusted models. The small number of cases with self-reported COPD $(n=15)$, all of whom were exposed to at least one VGDFFiM pollutant, prevented analysis of the relationship of VGDFFiM exposure and COPD.

Exposures in the longest held and current jobs were examined in separate models, which related self-reported COPD to any VGDFFiM in the longest job (OR 95\%CI 9.52 [1.09-83.32]) and FEV $_{1}<$ LLN to any VGDFFiM in both longest and current jobs (OR 95\%CI 4.51 [1.17-17.39] and $3.71[1.09-12.59]$ respectively). 
Approximately $10.4 \%(n=24)$ of the cohort reported a diagnosis of asthma only, $1.7 \%(n=4)$ a diagnosis of COPD only, and $4.3 \%(n=10)$ reported diagnoses of asthma and COPD. Inclusion of a diagnosis of asthma in the models demonstrated that after adjustment for self-reported asthma exposure to vapors and biological dusts were associated with $\mathrm{FEV}_{1}<\mathrm{LLN}$ (OR 95\%CI 6.94 [1.4633.1]) and (OR 95\%CI 3.97 [1.19-13.3]) respectively (Supplemental Material, Tables E2 and E3). 
Table 4 Associations between binary respiratory outcomes and exposure ever to occupational airborne pollutants in the WHEASE cohort in 2014: unadjusted and adjusted logistic regression analyses, $\mathrm{n}$ analyzed 237

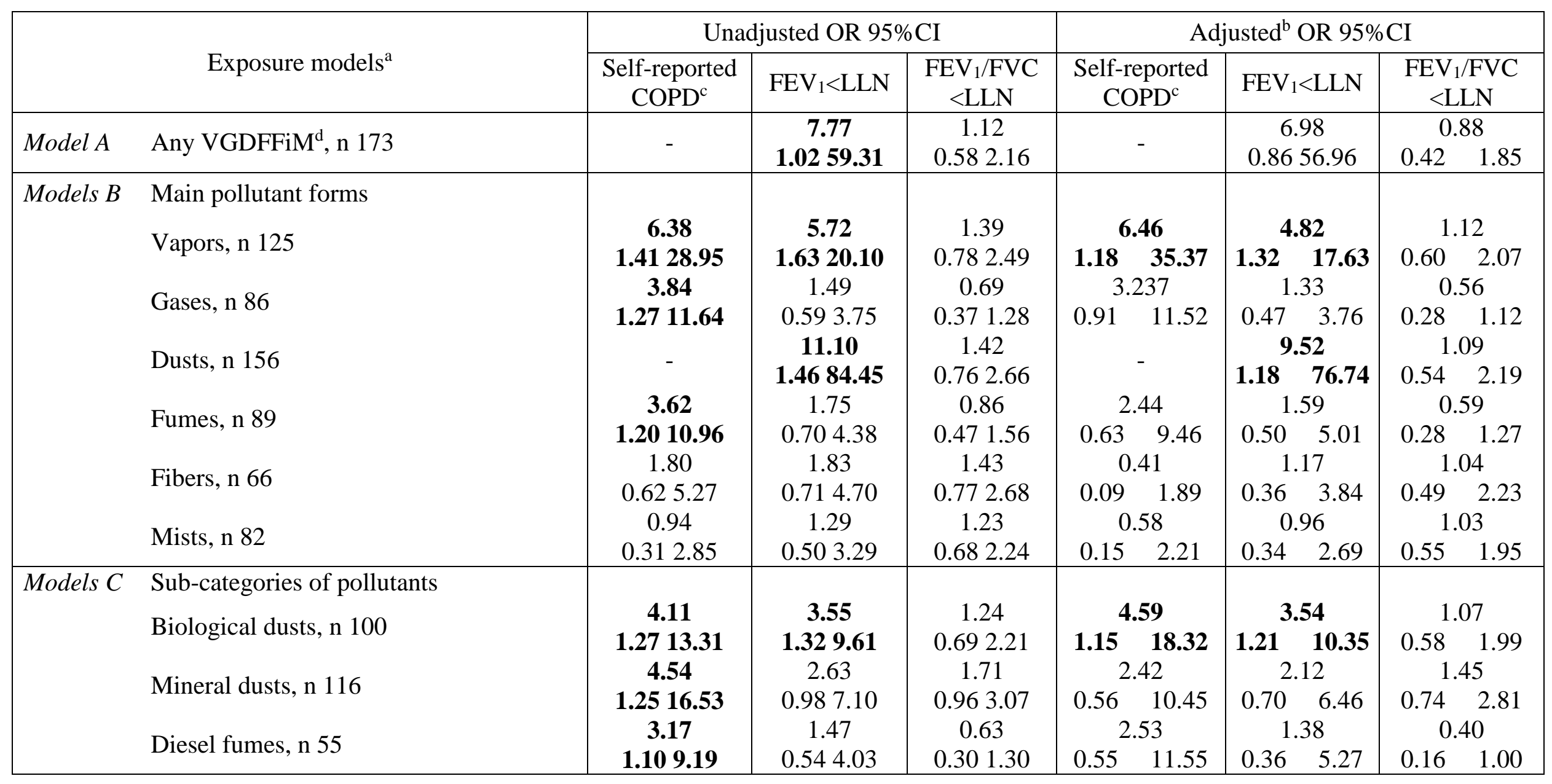



explore exposure to each sub-group of pollutant;

${ }^{\mathrm{b}}$ Adjusted for: sex, pack-years of smoking and educational attainment;

${ }^{c}$ No COPD diagnosis among not exposed to any VGDFFiM or Dusts;

${ }^{\mathrm{d}}$ Vapors, gases, dusts, fumes, fibers, mists.

Significant associations $(\mathrm{p}<0.05)$ highlighted in bold. 
Table 5 Associations between continuous respiratory outcomes and exposure ever to the occupational airborne pollutants in the WHEASE cohort in 2014: unadjusted and adjusted linear regression analyses, $\mathrm{n}$ analyzed 237

\begin{tabular}{|c|c|c|c|c|c|c|c|}
\hline & \multirow[b]{2}{*}{ Exposure models ${ }^{\mathrm{a}}$} & \multicolumn{3}{|c|}{ Unadjusted regression coefficient $95 \% \mathrm{CI}$} & \multicolumn{3}{|c|}{ Adjusted $^{\mathrm{b}}$ regression coefficient $95 \% \mathrm{CI}$} \\
\hline & & $\begin{array}{l}\mathrm{FEV}_{1} \% \\
\text { predicted }\end{array}$ & $\begin{array}{c}\text { FVC \% } \\
\text { predicted }\end{array}$ & $\begin{array}{c}\mathrm{FEF}_{25-75 \%} \% \\
\text { predicted }\end{array}$ & $\begin{array}{l}\mathrm{FEV}_{1} \% \\
\text { predicted }\end{array}$ & $\begin{array}{l}\text { FVC \% } \\
\text { predicted }\end{array}$ & $\begin{array}{c}\mathrm{FEF}_{25-75 \% \%} \% \\
\text { predicted }\end{array}$ \\
\hline \multirow{2}{*}{ Model A } & \multirow{2}{*}{ Any, VGDFFiM', n 173} & -2.16 & -1.34 & -1.84 & -1.18 & -2.17 & -0.17 \\
\hline & & -6.852 .54 & -5.813 .13 & -11.617 .94 & $-5.88 \quad 3.52$ & $-6.87 \quad 2.53$ & -10.109 .77 \\
\hline \multirow[t]{13}{*}{ Models B } & \multicolumn{7}{|l|}{ Main pollutant forms } \\
\hline & \multirow{2}{*}{ Vapors, n 125} & -5.28 & -2.87 & -10.78 & -3.27 & -2.10 & -6.88 \\
\hline & & $-9.41-1.16$ & -6.831 .09 & $-19.34-2.22$ & $-7.21 \quad 0.67$ & $-6.06 \quad 1.85$ & $-15.19 \quad 1.43$ \\
\hline & \multirow{2}{*}{ Gases, n 86} & -0.84 & -0.87 & -1.22 & -0.45 & -1.63 & -0.39 \\
\hline & & -5.183 .50 & -5.003 .26 & -10.237 .79 & $-4.61 \quad 3.73$ & $-5.81 \quad 2.54$ & $-9.19 \quad 8.42$ \\
\hline & \multirow{2}{*}{ Dusts, n 156} & -3.84 & -1.90 & -5.96 & -2.30 & -2.31 & -3.22 \\
\hline & & -8.210 .53 & -6.082 .29 & -15.073 .15 & $\begin{array}{ll}-6.68 & 2.08\end{array}$ & $-6.70 \quad 2.08$ & -12.486 .04 \\
\hline & \multirow{2}{*}{ Fumes, n 89} & -2.21 & -2.83 & 1.42 & -2.36 & -5.89 & 2.48 \\
\hline & & -6.512 .10 & -6.921 .26 & -7.5010 .35 & $\begin{array}{ll}-7.07 & 2.35\end{array}$ & $-10.55-1.22$ & $\begin{array}{ll}-7.48 & 12.43\end{array}$ \\
\hline & \multirow{2}{*}{ Fibers, n 66} & -3.64 & -1.04 & -4.53 & -2.02 & -2.01 & -1.56 \\
\hline & & -8.280 .00 & -5.473 .39 & -14.155 .09 & $\begin{array}{ll}-6.95 & 2.92\end{array}$ & $-6.95 \quad 2.93$ & -11.968 .84 \\
\hline & \multirow{2}{*}{ Mists, n 82} & -0.84 & -0.37 & -1.27 & 0.98 & 0.57 & 2.49 \\
\hline & & -5.233 .54 & -4.543 .81 & -10.387 .84 & $\begin{array}{ll}-3.15 \quad 5.11 \\
\end{array}$ & $\begin{array}{ll}-3.57 & 4.71 \\
\end{array}$ & $-6.24 \quad 11.23$ \\
\hline \multirow[t]{6}{*}{ Models $C$} & \multicolumn{7}{|l|}{ Sub-categories of pollutants } \\
\hline & \multirow[t]{2}{*}{ Biological dusts, n 100} & -4.75 & -2.99 & -11.47 & -3.58 & -2.53 & -9.11 \\
\hline & & $\mathbf{- 8 . 9 4 - 0 . 5 7}$ & -6.991 .02 & $-20.11-2.83$ & $\begin{array}{ll}-7.51 & 0.34\end{array}$ & $\begin{array}{ll}-6.47 & 1.42\end{array}$ & $-17.38-0.84$ \\
\hline & \multirow[t]{2}{*}{ Mineral dusts, n 116} & -3.08 & -1.42 & -2.47 & -1.87 & -2.24 & 0.19 \\
\hline & & $\begin{array}{l}-2.96 \\
-241.00\end{array}$ & $\begin{array}{c}-5.392 .55 \\
-339\end{array}$ & $\begin{array}{l}1.120 .19 \\
-016\end{array}$ & $\begin{array}{c}-6.13 \quad 2.40 \\
-3.97\end{array}$ & $\begin{array}{c}-6.5142 .026 \\
-7.02\end{array}$ & $\begin{array}{c}-8.829 .20 \\
-100\end{array}$ \\
\hline & Diesel fumes, n 55 & -7.891 .97 & -8.071 .30 & -10.3910 .07 & $-9.28 \quad 1.34$ & $-12.28-1.76$ & -12.2410 .23 \\
\hline
\end{tabular}

${ }^{a}$ Model A explores the binary exposure to any of the six main pollutant forms, models B explore exposure to each main pollutant form, models C explore exposure to each sub-group of pollutant; 
${ }^{\mathrm{b}}$ Adjusted for: sex, pack-years of smoking and educational attainment;

${ }^{c}$ Vapors, gases, dusts, fumes, fibers, mists.

Significant associations $(\mathrm{p}<0.05)$ highlighted in bold. 
Analyses of the relationship between the lung function outcomes and cumulative duration of exposure demonstrated evidence for dose-response associations between exposure to VGDFFiM and $\mathrm{FEV}_{1}<\mathrm{LLN}$, with 16-times increased likelihood of $\mathrm{FEV}_{1}<\mathrm{LLN}$ in those with high duration of exposure (Table 6). There was no association between exposure duration and FEV $1 / \mathrm{FVC}<\mathrm{LLN}$. 
Table 6 Associations between lung function outcomes and cumulative duration of exposure to occupational airborne pollutants in the WHEASE cohort in 2014; adjusted logistic and linear regression analyses, $n$ analyzed 237

\begin{tabular}{|c|c|c|c|c|c|c|c|c|c|c|c|c|}
\hline \multirow{2}{*}{ Exposure } & \multirow{2}{*}{$\begin{array}{l}\text { Categories } \\
\text { of duration }\end{array}$} & \multirow{2}{*}{$\mathrm{N}$} & \multicolumn{4}{|c|}{$\begin{array}{c}\text { Adjusted }^{\mathrm{b}} \text { OR } \\
95 \% \mathrm{CI}\end{array}$} & \multicolumn{6}{|c|}{$\begin{array}{c}\text { Adjusted }^{\mathrm{b}} \mathrm{B} \\
95 \% \mathrm{CI}\end{array}$} \\
\hline & & & \multicolumn{2}{|c|}{$\mathrm{FEV}_{1}<\mathrm{LLN}$} & \multicolumn{2}{|c|}{$\mathrm{FEV}_{1} / \mathrm{FVC}<\mathrm{LLN}$} & \multicolumn{2}{|c|}{$\mathrm{FEV}_{1} \%$ predicted } & \multicolumn{2}{|c|}{ FVC $\%$ predicted } & \multicolumn{2}{|c|}{$\mathrm{FEF}_{25-75 \%} \%$ predicted } \\
\hline \multirow{4}{*}{$\begin{array}{c}\text { Any } \\
\text { VGDFFiM }^{c}\end{array}$} & None & 64 & - & \multirow{4}{*}{$\begin{array}{l}\text { p-trend } \\
0.004\end{array}$} & - & \multirow{4}{*}{$\begin{array}{c}\mathrm{p} \text {-trend } \\
0.915\end{array}$} & - & \multirow{4}{*}{$\begin{array}{c}p \text { trend } \\
0.828\end{array}$} & - & \multirow{4}{*}{$\begin{array}{l}\mathrm{p} \text { trend } \\
0.236\end{array}$} & - & \multirow{4}{*}{$\begin{array}{l}p \text { trend } \\
0.997\end{array}$} \\
\hline & Short & 59 & $\begin{array}{c}4.06 \\
0.42,39.40 \\
\end{array}$ & & $\begin{array}{c}1.01 \\
0.44,2.37 \\
\end{array}$ & & $\begin{array}{c}-0.68 \\
-6.08,4.73 \\
\end{array}$ & & $\begin{array}{c}-1.10 \\
-6.47,4.27 \\
\end{array}$ & & \begin{tabular}{|c|}
0.40 \\
$-11.01,11.82$ \\
\end{tabular} & \\
\hline & Med & 59 & $\begin{array}{c}5,84 \\
0.59,57.86\end{array}$ & & $\begin{array}{c}0.58 \\
0.22,1.50\end{array}$ & & $\begin{array}{c}-2.46 \\
-8.10,3.18\end{array}$ & & $\begin{array}{c}-5.07 \\
-10.67,0.54\end{array}$ & & $\begin{array}{c}-0.30 \\
-12.20,11.61\end{array}$ & \\
\hline & Long & 55 & $\begin{array}{c}15.79 \\
1.72,144.53\end{array}$ & & $\begin{array}{c}1.10 \\
0.44,2.76\end{array}$ & & $\begin{array}{c}-0.42 \\
-6.29,5.46\end{array}$ & & $\begin{array}{c}-0.31 \\
-6.15,5.54\end{array}$ & & \begin{tabular}{|c|}
-0.95 \\
$-13.41,11.52$
\end{tabular} & \\
\hline
\end{tabular}

${ }^{a}$ The categories were generated using tertiles of cumulative lifetime duration of exposure in years to any of the six main pollutant forms

${ }^{\mathrm{b}}$ Adjusted for: sex, pack-years of smoking and educational attainment.

${ }^{c}$ Vapors, gases, dusts, fumes, fibers, mists

Significant associations $(\mathrm{p}<0.05)$ highlighted in bold. 


\subsection{Longitudinal analysis of lung function outcomes between 1989 and 2014 in relation to}

occupational exposure to airborne chemical pollutants

Spirometry data were collected in the WHEASE cohort in 1989, 1995, 2001 and 2014. For longitudinal analysis of lung function between 1989 and 2014 spirometry records were available on 191 subjects at three time points and on 45 subjects at two time points, with a total number of 663 records for the 237 subjects without childhood wheezing illness. The results of linear mixed effects modelling to assess the overall effect of lifetime binary (yes/no) exposure to airborne pollutants on $\mathrm{FEV}_{1}, \mathrm{FVC}$ and $\mathrm{FEF}_{25-75 \%}$ between 1989 and 2014 are presented in Table 7. When compared to those not exposed, participants exposed to biological dusts or vapors had significantly reduced $\mathrm{FEV}_{1}$ and $\mathrm{FEF}_{25-75 \%} \%$ predicted, while those exposed to diesel fumes had reduced $\mathrm{FEV}_{1}$ and $\mathrm{FVC}$ $\%$ predicted. Repeating models to assess exposures in the longest held and current/last held jobs demonstrated similar but less marked results (Supplemental Material, Tables E4 and E5). Exposure to any VGDFFiM was not related to lung function parameters in longitudinal analyses.

Consistent significant associations between exposures and outcomes in Table 7 were further analyzed in linear mixed effects models to assess the effect of lifetime cumulative duration of exposure. Table 8 presents results of these analyses. It shows evidence for significant trends across a range of exposures and outcomes, particularly consistent for vapors, cumulative duration of exposure to which was related to reduced estimates of differences in $\mathrm{FEV}_{1}, \mathrm{FVC}$, and $\mathrm{FEF}_{25-75 \%} \%$ predicted. 
Table 7. Adjusted linear mixed effects modelling applied to all lung function data collected between 1989 and 2014 in the WHEASE cohort, estimates of differences in $\mathrm{FEV}_{1}, \mathrm{FVC}$, and $\mathrm{FEF}_{25-75 \%} \%$ predicted between ever exposed and not exposed to occupational airborne pollutants $(n=237$, records analyzed $n=663$ )

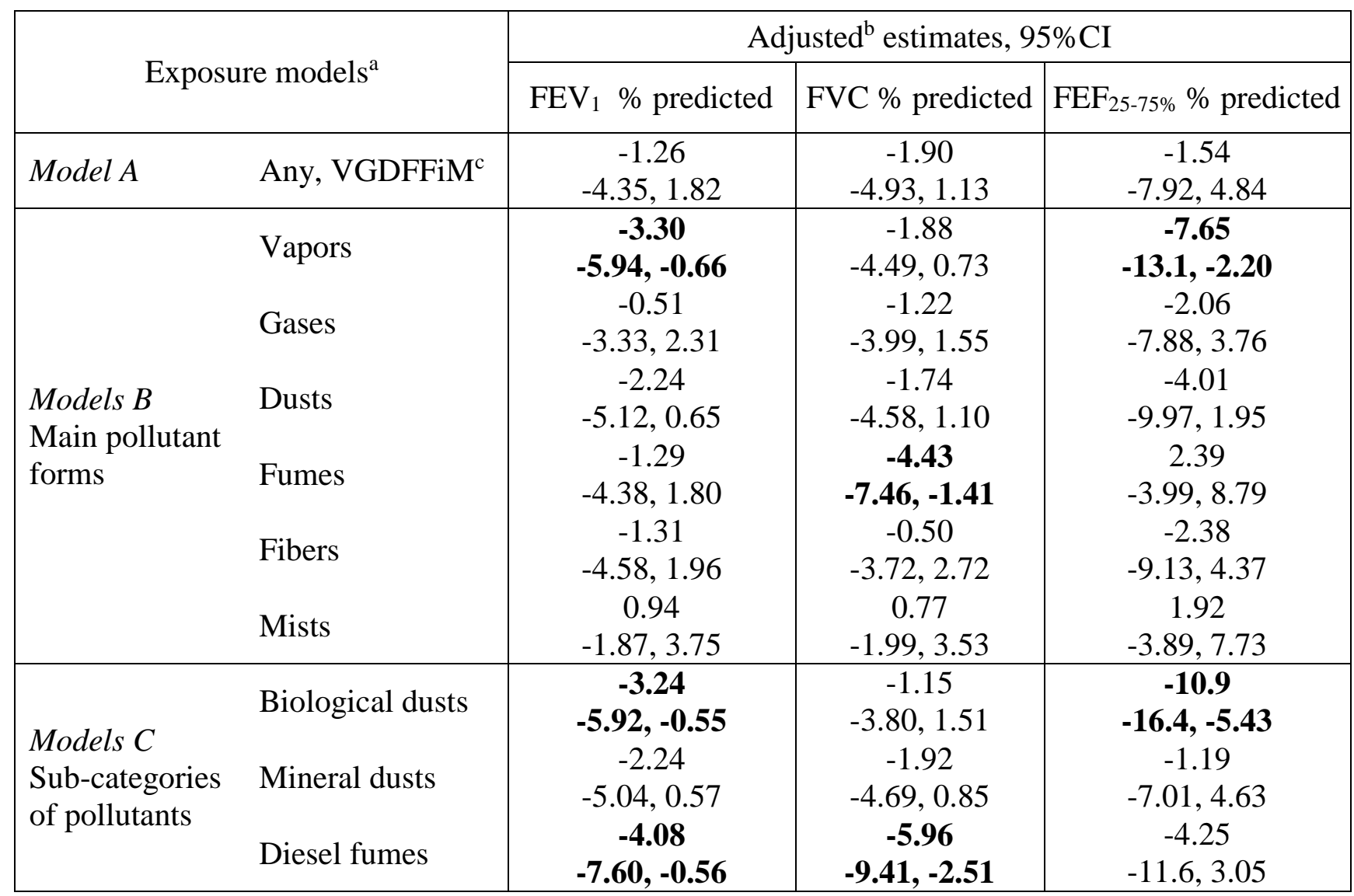

${ }^{a}$ Model A explores the binary exposure to any of the six main pollutant forms, models B explore exposure to each main pollutant form, models $\mathrm{C}$ explore exposure to each sub-group of pollutant.

${ }^{\mathrm{b}}$ Adjusted for sex, age in 1989, pack-years of smoking, and educational attainment;

${ }^{c}$ Vapors, gases, dusts, fumes, fibers, mists.

Significant associations $(\mathrm{p}<0.05)$ highlighted in bold. 
Table 8 Adjusted linear mixed effects modelling applied to all lung function data collected between 1989 and 2014 in the WHEASE cohort; estimates of differences in $\mathrm{FEV}_{1}, \mathrm{FVC}$, and $\mathrm{FEF}_{25-75 \%} \%$ predicted between categories of cumulative duration of exposure to occupational airborne pollutants $(\mathrm{n}=237$, records analyzed $\mathrm{n}=663)$

\begin{tabular}{|c|c|c|c|c|c|c|c|}
\hline \multirow{2}{*}{$\begin{array}{c}\text { Exposure } \\
\text { to }\end{array}$} & \multirow{2}{*}{$\begin{array}{c}\text { Categories } \\
\text { of } \\
\text { duration }^{\mathrm{a}}\end{array}$} & \multicolumn{6}{|c|}{ Adjusted $^{\mathrm{b}}$ estimates OR 95\%CI } \\
\hline & & \multicolumn{2}{|c|}{$\mathrm{FEV}_{1} \%$ predicted } & \multicolumn{2}{|c|}{ FVC \% predicted } & \multicolumn{2}{|c|}{$\mathrm{FEF}_{25-75 \%} \%$ predicted } \\
\hline Vapors & $\begin{array}{l}\text { None } \\
\text { Short } \\
\text { Med } \\
\text { Long }\end{array}$ & $\begin{array}{c}\mathbf{- 4 . 7 9} \\
\mathbf{- 8 . 1 5 ,}-\mathbf{- 1 . 4 4} \\
\mathbf{- 3 . 8 9} \\
\mathbf{- 7 . 1 0}, \mathbf{- 0 . 6 8} \\
-1.23 \\
-4.45,1.99\end{array}$ & $\begin{array}{c}\text { p-trend } \\
0.013\end{array}$ & $\begin{array}{c}\mathbf{- 6 . 2 8} \\
\mathbf{- 9 . 6 0}, \mathbf{- 2 . 9 7} \\
0.11 \\
-3.05,3.28 \\
-0.10 \\
-3.28,3.07\end{array}$ & $\begin{array}{c}\text { p-trend } \\
\mathbf{0 . 0 0 2}\end{array}$ & $\begin{array}{c}-3.61 \\
-10.6,3.34 \\
\mathbf{- 1 0 . 1} \\
\mathbf{- 1 6 . 7 , - 3 . 4 6} \\
\mathbf{- 7 . 9 8} \\
\mathbf{- 1 4 . 7 , - 1 . 2 6}\end{array}$ & $\begin{array}{c}\text { p-trend } \\
\mathbf{0 . 0 1 0}\end{array}$ \\
\hline $\begin{array}{l}\text { Biological } \\
\text { dusts }\end{array}$ & $\begin{array}{l}\text { None } \\
\text { Short } \\
\text { Med } \\
\text { Long }\end{array}$ & $\begin{array}{c}-1.71 \\
-5.26,1.84 \\
-\mathbf{7 . 4 2} \\
\mathbf{- 1 0 . 8 , - 4 . 0 4} \\
-0.41 \\
-3.83,3.01 \\
\end{array}$ & $\begin{array}{c}p \text { p-trend } \\
<0.001\end{array}$ & $\begin{array}{c}-1.68 \\
-8.25,188 \\
-1.39 \\
-4.78,2.00 \\
-1.42 \\
-4.85,2.01 \\
\end{array}$ & $\begin{array}{c}\mathrm{p} \text {-trend } \\
0.664\end{array}$ & $\begin{array}{c}\mathbf{- 8 . 9 8} \\
\mathbf{- 1 6 . 4 , - 1 . 6 1} \\
\mathbf{- 1 9 . 5} \\
\mathbf{- 2 6 . 4 ,}-\mathbf{- 1 2 . 6} \\
-2.24 \\
-9.25,4.77 \\
\end{array}$ & $\begin{array}{c}p \text {-trend } \\
<0.001\end{array}$ \\
\hline $\begin{array}{l}\text { Diesel } \\
\text { fumes }\end{array}$ & $\begin{array}{l}\text { None } \\
\text { Short } \\
\text { Med } \\
\text { Long }\end{array}$ & $\begin{array}{c}-1.94 \\
-7.01 .3 .13 \\
-\mathbf{3 . 6 7} \\
\mathbf{- 7 . 9 5 , - 0 . 6 1} \\
-\mathbf{7 . 1 6} \\
\mathbf{- 1 2 . 1 , - 2 . 2 4}\end{array}$ & $\begin{array}{c}\text { p-trend } \\
0.026\end{array}$ & $\begin{array}{c}-2.68 \\
-7.66,2.31 \\
\mathbf{- 6 . 4 1} \\
\mathbf{- 1 0 . 6 , - 2 . 2 0} \\
\mathbf{- 9 . 5 0} \\
\mathbf{- 1 4 . 3 ,}-\mathbf{- 4 . 6 6}\end{array}$ & $\begin{array}{c}p \text {-trend } \\
<0.001\end{array}$ & $\begin{array}{c}-5.65 \\
-16.2,4.92 \\
-2.15 \\
-11.1,6.77 \\
-4.58 \\
-04.8,5.67\end{array}$ & $\begin{array}{c}\mathrm{p} \text {-trend } \\
0.645\end{array}$ \\
\hline
\end{tabular}

${ }^{\text {a }}$ Categories were generated using tertiles of cumulative lifetime duration of exposure in years

${ }^{\text {b} A d j u s t e d ~ f o r: ~ s e x, ~ a g e ~ i n ~ 1989, ~ p a c k ~ y e a r s ~ o f ~ s m o k i n g, ~ a n d ~ e d u c a t i o n a l ~ a t t a i n m e n t . ~}$

Significant associations $(\mathrm{p}<0.05)$ highlighted in bold. 


\section{Discussion}

This is the first community-based study to examine the association of lifetime occupational exposure to total and specific forms of airborne pollutants with lung function and self-reported COPD in older adults who had had no preceding childhood wheezing illness. Lifetime occupational exposure to biological dusts or vapors was independently associated with self-reported COPD and reduced lung function at age 58-64 years, and was also linked to overall impaired lung function observed between ages 35 and 64 years. In addition, significant trends were demonstrated between lung function and the duration of exposure to any of the six airborne pollutant forms (VGDFFiM) in the cross-sectional analyses and between lung function and the duration of exposure to biological dusts and vapors in the longitudinal analyses. The study found no link between any respiratory outcomes and exposure to gases, fibers, mists or mineral dusts while associations between reduced $\mathrm{FEV}_{1}$ or $\mathrm{FVC} \%$ predicted and exposure to diesel fumes were demonstrated only in longitudinal analyses. There is a substantial body of evidence from occupational-based studies linking COPD and obstructive lung function impairment with exposure to specific dust type [3]. Population-based evidence is, however, less certain. Most population studies investigate the role of total occupational dust exposure [23]. Some, similar to the current study, report associations with exposure to biological but not mineral dusts [24], while others demonstrate associations with organic (biological) but not mineral [25], with both [5;26] or did not find associations with either [4] types of dust. In contrast, evidence for the association between the exposure to biological dusts and an increased prevalence of chronic bronchitis and respiratory symptoms is more consistent and has been increasingly recognized [24]. The prevalence of exposure to biological or mineral dusts in the current study was generally in agreement with findings of other population-based studies [4;24].

Although the current study found the association between exposure to biological dusts and selfreported COPD, in agreement with some [4] but not other reports [5] the association with 
spirometric COPD $\left(\mathrm{FEV}_{1} / \mathrm{FVC}<\mathrm{LLN}\right)$ was not significant $(\mathrm{p}=0.099)$ despite the similar trend. Although the association between biological dusts and self-reported COPD is consistent with our findings of associations with reduced $\mathrm{FEV}_{1}$ and reduced $\mathrm{FEF}_{25-75}$ and no association with $\mathrm{FVC}$, the lack of association with spirometric evidence of $\mathrm{COPD}\left(\mathrm{FEV}_{1} / \mathrm{FVC}<\mathrm{LLN}\right)$ may be a consequence of National COPD Guidelines that advise clinicians to diagnose COPD based on FEV1/FVC $<0.7$ rather than $\mathrm{FEV}_{1} / \mathrm{FVC}<\mathrm{LLN}$. Others have also reported an association between exposure to biological dusts and severe COPD $\left(\mathrm{FEV}_{1}<30 \%\right)$ and COPD with dyspnea/sputum, but not with mild or moderate airflow obstruction [24].

Biological dusts are mixtures of agents of biological origin including grains, flours, woods, dander, endotoxin and other parts and metabolites from plants, animals, insects, bacteria, and fungi. These are found in many workplaces, e.g. handling/processing food, cotton, animals, manufacturing and construction [27]. In the WHEASE cohort subjects exposed to biological dusts in the longest job held were more commonly engaged in occupational groups such as skilled trades occupations (e.g. in agriculture, textiles, construction) and personal service occupations (e.g. in health and social care services). The ACEJEM used in this study defines biological dusts as those, which originate from plant and wood sources (flour dusts, wood and cotton) as well as micro-organisms i.e. it includes both biological and organic dusts. These agents have potential to elicit inflammatory responses that may lead to the development of COPD [28].

Similar associations between exposure to biological dusts and $\mathrm{FEV}_{1}$ and $\mathrm{FEF}_{25-75 \%}$ were found in the longitudinal analyses of all data collected between 1989 and 2014. The longitudinal analyses also demonstrated associations between exposure to vapors and $\mathrm{FEV}_{1}, \mathrm{FVC}$, and $\mathrm{FEF}_{25-75 \%}$ and exposure to diesel fumes and $\mathrm{FEV}_{1}$ and FVC. Although an association between exposures to vapors and $\mathrm{FEV}_{1}<\mathrm{LLN}$ was evident on cross-sectional analysis there were no associations with diesel 
exposure in the cross-sectional analysis. Whilst the longitudinal analyses for biological dusts and vapors are consistent with the cross-sectional analyses, the associations with diesel fumes demonstrated on longitudinal but not cross-sectional analyses may be a consequence of the relatively small sample size of the 2014 follow-up, while the longitudinal analysis included 663 records of data spanning between 1989 and 2014.

In occupational settings vapors usually arise from substances and compounds which contain volatile liquids including solvents, paints, glues, adhesives, and polishes [21]. In the WHEASE cohort the most common occupations with exposure to vapors were cleaners and managers working in production including factory managers. Subjects exposed to any fumes were more likely to work as production managers (including factory managers) and machine and mechanical fitters, while those exposed to diesel fumes worked as van drivers or factory laborers. Most individuals, however, were exposed to more than one occupational pollutant, e.g. carpenters were exposed to vapors from paints and glues as well as wood dusts. The mechanism of action is dependent on the specific substance (toxicity), pattern of exposure and co-exposures.

Physician diagnosed and self-reported asthma is a strong risk factor for COPD [29;30] and in this study $10.4 \%$ of the participants reported a diagnosis of asthma, $1.7 \%$ a diagnosis of COPD, and 4.3\% reported diagnoses of asthma and COPD. Although after adjustment for self-reported asthma there were no associations between occupational exposures and the small numbers of self-reported COPD, occupational exposure to vapors and biological dusts was still adversely associated with $\mathrm{FEV}_{1}<\mathrm{LLN}$. Although numbers are small this suggests that whilst most of the associations reported between occupational exposures and COPD may perhaps be the long-term consequence of asthma, exposure to vapors and biological dusts have adverse effects on $\mathrm{FEV}_{1}$ independent of any effect of 
asthma. A much larger study is required to determine whether any association between occupational exposures and COPD is independent of asthma.

In disagreement with other studies that used a JEM for exposure assessment [5], the current study did not find an association between spirometric COPD and occupational exposure to any of the main pollutant forms. The current study, however, similar to previous reports [31], found a marked dose-response relationship between reduced $\mathrm{FEV}_{1}$ and the cumulative duration of exposure to the major pollutant forms (VGDFFiM). A link between $\mathrm{FEV}_{1}$ and exposure to any VGDFFiM was consistently demonstrated for both the longest and current jobs. No relationship was found between duration of exposure to specific groups of airborne pollutants and outcomes in cross-sectional analyses of lung function data collected in 2014, which is in agreement with some [24] but not other studies that reported, for example, an increased risk of COPD [32] and reduced $\mathrm{FEV}_{1}$ [31] with increased exposure to biological dusts. However, using all lung function data collected between 1989 and 2014 demonstrated significant trends across duration of exposure to vapors, biological dusts, and diesel fumes.

The major strength of the study was the ability to examine the impact of occupational exposure over a working lifetime on adult airway disease in individuals who did not have childhood wheezing illness. Childhood wheezing illness is an increasingly recognized risk factor for adult COPD [10] and therefore children with wheezing illness were excluded. It is, however, possible that parents would not have recalled or forgotten to report mild/transient wheeze in their children, and these children would then have been wrongly classified and included in this study. In this WHEASE cohort, however, those with no reported childhood wheeze had significantly less risk of developing COPD defined as post-bronchodilator $\mathrm{FEV}_{1} / \mathrm{FVC}<\mathrm{LLN}$ compared to those with childhood asthma or "wheezy bronchitis"/virus-associated wheeze [10]. 
Examining the relation between exposures and outcomes in a population-based study reduced the risk of healthy-worker and responder biases. Detailed lifetime occupational histories were, however, collected retrospectively, and as a result some earlier short-term jobs may not have been recalled, although these are unlikely to be important unless they included extremely toxic exposures. Prospective respiratory data analysis and length of follow-up (50-years) are other strengths, as well as objective measurement of lung function in addition to self-reported COPD. Another strength was using the ACEJEM, which is the UK occupation based JEM, covering the complete range of airborne occupational pollutants, that assigns exposure to SOC 2000 codes. It is also one of few JEMs for which detailed methodology for assigning exposures has been published [21]. ACEJEM, however, provides general population exposure estimates, which are based on consensus amongst occupational experts with exposure assigned following a set of guidelines and not based on quantified personal exposure measurement. To our knowledge there are currently no UK general population JEMs that are validated for estimating exposure levels to different occupational airborne pollutant forms. Given the relatively small sample size the intensity and probability of exposure could not be considered and only the binary component of ACEJEM was used in the present study analyses. The inaccuracy of exposure assessment and insufficient precision of its estimation by population-specific JEM in small-size studies [24;33] is, however, a possible limitation.

The high prevalence of smoking in the cohort population might have introduced the risk of bias due to residual confounding affecting the observed association with occupational exposures of interest, however, using quantified estimates of lifetime exposure to cigarette smoking minimized this bias. 
The main limitation of this study was the relatively small numbers of participants who were exposed to airborne pollutants, resulting in insufficient statistical power to explore associations between exposures and outcomes. This could have reduced the chance of detecting an effect, e.g. on spirometric airflow obstruction or the relationship between self-reported COPD and VGDFFiM. Exposures associated with heavy industry may have also been under-represented, as they were limited to those experienced while working in semi-rural North East of Scotland. Estimates of exposure were limited to the broad pollutant forms rather than specific substances. Changes in workplace environment/exposures since 1964, using control measures at work or personal compliance with safety regulations also may have influenced the findings. It is also important to note that most WHEASE study participants were exposed to different airborne pollutants in combination or consequentially within the same job or during their working lives. Multiple exposures to different pollutants present a challenge to the evaluation of the association between outcomes and a single pollutant type. A further limitation was that the cohort was not designed to prospectively investigate the association between occupational exposures and respiratory health and a "non-systematic" approach in selection and follow up could have introduced a selection bias and affected the representativeness of the sample. We cannot rule out the possibility of a response bias favoring participation by concerned individuals with minor symptoms of airflow obstruction and health worries. This may explain the slight reduction in $\mathrm{FEV}_{1}(97 \%$ predicted) and increased FVC (109\% predicted) observed in the study participants. The analysis exploring socio-demographic characteristics of the cohort in 1989, 1994, 2001 and 2014, however, found no difference in sex and smoking history, although there was a higher prevalence of more affluent participants in 2014. Although multiple tests were performed in the current study, to minimize the possibility of false conclusions about causal associations, only consistent associations were considered and examined further. 


\section{Conclusions}

Occupational exposure to biological dusts and vapors increased the risk of reduced lung function over 50 years in people who did not have childhood wheezing illness. The risk was also higher for those with longer years of lifetime exposure to these pollutants compared to those with shorter exposure duration.

Exposure to biological dusts or vapors also increased the risk of self-reported COPD. There is therefore a need for increased awareness of the links between occupational exposure to certain pollutants and respiratory conditions among the general public. The low number of subjects, however, warrants caution in interpretation of the study findings. The association between biological dusts and vapors and lung function impairment requires further investigation in larger population-based studies. 


\section{Funding}

This study was funded by Chest, Heart and Stroke Scotland, grant number R13/A148.

The funder had no role in study design, data collection, analysis and interpretation, writing of the manuscript, and in the decision to submit the manuscript for publication. All authors had full access to all the data in the study. The corresponding author had final responsibility for the decision to submit for publication.

\section{Conflicts of Interest}

The authors declare no direct or indirect conflicts of interest

\section{Review and approval}

National Research Ethics Service Committee - North of Scotland, ref 13/NS/0038 


\section{Reference List}

1. European Respiratory Society, European Lung Foundation. Occupational lung diseases. In: Gibson GJ, Loddenkemper R, Sibille Y, Lundback B, Fletcher M, editors. The European Lung White Book. Sheffield, UK: European Lung Foundation, 2013:282-95.

2. Fishwick D, Sen D, Barber C, Bradshaw L, Robinson E, Sumner J. Occupational chronic obstructive pulmonary disease: a standard of care. Occup.Med (Lond) 2015;65(4):270282.

3. Omland O, Wurtz ET, Aasen TB et al. Occupational chronic obstructive pulmonary disease: a systematic literature review. Scand.J Work Environ.Health 2014;40(1):19-35.

4. Sunyer J, Zock JP, Kromhout $\mathrm{H}$ et al. Lung function decline, chronic bronchitis, and occupational exposures in young adults. Am J Respir Crit Care Med 2005;172(9):1139-45.

5. Mehta AJ, Miedinger D, Keidel D et al. Occupational exposure to dusts, gases, and fumes and incidence of chronic obstructive pulmonary disease in the Swiss Cohort Study on Air Pollution and Lung and Heart Diseases in Adults. Am J Respir Crit Care Med 2012;185(12):1292-300.

6. Humerfelt S, Gulsvik A, Skjaerven R et al. Decline in FEV1 and airflow limitation related to occupational exposures in men of an urban community. Eur.Respir.J 1993;6(8):1095103. 
7. Kauffmann F, Drouet D, Lellouch J, Brille D. Occupational exposure and 12-year spirometric changes among Paris area workers. Br.J Ind.Med 1982;39(3):221-32.

8. de Jong K, Boezen HM, Kromhout H, Vermeulen R, Postma DS, Vonk JM. Association of Occupational Pesticide Exposure With Accelerated Longitudinal Decline in Lung Function. Am.J.Epidemiol. 2014;179(11):1323-30.

9. Le MN, Kauffmann F, Eisen EA, Kennedy SM. The healthy worker effect in asthma: work may cause asthma, but asthma may also influence work. Am J Respir Crit Care Med 2008;177(1):4-10.

10. Tagiyeva N, Devereux G, Fielding S, Turner S, Douglas G. Outcomes of Childhood Asthma and Wheezy Bronchitis - a 50-year Cohort Study. Am.J.Respir.Crit.Care Med. 2016;193(1):23-30.

11. Dawson B, Illsley R, Horobin G, Mitchell R. A survey of childhood asthma in Aberdeen. Lancet 1969;1(7599):827-30.

12. Fletcher CM. Standardised questionnaire on respiratory symptoms: a statement prepared and approved by the MRC Committee on the Aetiology of Chronic Bronchitis (MRC breathlessness score). BMJ 1960;2(5213):1665.

13. Bodner C, Ross S, Little J et al. Risk Factors for Adult Onset Wheeze . A Case Control Study. Am.J.Respir.Crit.Care Med. 1998;157(1):35-42. 
14. Edwards CA, Osman LM, Godden DJ, Douglas JG. Wheezy bronchitis in childhood: a distinct clinical entity with lifelong significance? Chest 2003;124(1):18-24.

15. Godden DJ, Ross S, Abdalla M et al. Outcome of wheeze in childhood. Symptoms and pulmonary function 25 years later. Am J Respir Crit Care Med 1994;149(1):106-12.

16. Medical Research Council. Medical Research Council's Committee on Environmental and Occupational Health: Questionnaire on respiratory symptoms. 1986. London, MRC.

17. Pellegrino R, Viegi G, Brusasco V et al. Interpretative strategies for lung function tests. Series "ATS/ERS Task Force: Standardisation of lung function testing". Eur.Respir.J. 2005;26(5):948-68.

18. Office for National Statistics. Standard Occupational Classification 2000. National Statistics.

19. Jones, R. and Elias, P. 2006. CASCOT: Computer-assisted Structured Coding Tool. Institute for Employment Research. Coventry, University of Warwick.

20. Tagiyeva N, Devereux G, Semple S et al. Parental occupation is a risk factor for childhood wheeze and asthma. Eur.Respir.J. 2010;35(5):987-93.

21. Sadhra S, Kurmi O, Chambers H, Lam K, Fishwick D, The Occupational COPD Research Group. Development of an occupational airborne chemical exposure matrix. Occup.Med. 2016;66(5):358-64 
22. Quanjer PH, Stanojevic S, Cole TJ et al. Multi-ethnic reference values for spirometry for the 3-95-yr age range: the global lung function 2012 equations. Eur.Respir.J. 2012;40(6):1324-43.

23. Harber P, Tashkin DP, Simmons M, Crawford L, Hnizdo E, Connett J. Effect of occupational exposures on decline of lung function in early chronic obstructive pulmonary disease. Am J Respir Crit Care Med 2007;176(10):994-1000.

24. Matheson MC, Benke G, Raven J et al. Biological dust exposure in the workplace is a risk factor for chronic obstructive pulmonary disease. Thorax 2005;60(8):645-51.

25. Weinmann S, Vollmer WM, Breen V et al. COPD and occupational exposures: a casecontrol study. J Occup.Environ.Med 2008;50(5):561-69.

26. Mastrangelo G, Tartari M, Fedeli U, Fadda E, Saia B. Ascertaining the risk of chronic obstructive pulmonary disease in relation to occupation using a case-control design. Occup.Med (Lond) 2003;53(3):165-72.

27. Rim KT, Lim CH. Biologically hazardous agents at work and efforts to protect workers' health: a review of recent reports. Saf Health Work 2014;5(2):43-52.

28. Thorn J. The inflammatory response in humans after inhalation of bacterial endotoxin: a review. Inflamm.Res. 2001;50(5):254-61.

29. Silva GE, Sherrill DL, Guerra S, Barbee RA. Asthma as a risk factor for COPD in a Longitudinal Study. Chest. 2004;126(1):59-65. 
30. Lange P, Parner J, Vestbo J, Schonhr P, Jensen G. A 15-year follow-up study of ventilatory function in adults with asthma. N Engl J Med 1998; 339: 1194-200

31. Le Moual N, Orlowski E, Schenker MB, Avignon M, Brochard P, Kauffmann F. Occupational exposures estimated by means of job exposure matrices in relation to lung function in the PAARC survey. Occup.Environ.Med. 1995;52(10):634-43.

32. Govender N, Lalloo UG, Naidoo RN. Occupational exposures and chronic obstructive pulmonary disease: a hospital based case-control study. Thorax 2011;66(7):597-601.

33. Le Moual N, Bakke P, Orlowski E et al. Performance of population specific job exposure matrices (JEMs): European collaborative analyses on occupational risk factors for chronic obstructive pulmonary disease with job exposure matrices (ECOJEM). Occup Environ Med 2000;57(2):126-32 